Faculty and PostDoc, Energy and Environment

\title{
Preliminary Investigation of Heavy Metals in Deposited Dust on Roadside Sidr Leaves
}

\author{
Noora Al-Naimi ${ }^{1}$, Hamood Al-Saadi ${ }^{1}$, Ahmed Abou Elezz ${ }^{1}$, Maryam Al-Adba ${ }^{1}$, Hassan Hassan $^{1}$ \\ ${ }^{1}$ Environmental Science Center, Qatar University
}

4

\section{Introduction}

Traffic emissions are known as potential pollutants. These contaminants have a negative impact on roadside vegetation. Someroadsideplants are capableofabsorbingsignificantamounts of heavy metals; and thus, could be helpful as biomonitors of environmental pollution. Metals such as iron $(\mathrm{Fe})$, cadmium $(\mathrm{Cd})$, lead $(\mathrm{Pb})$, copper $(\mathrm{Cu})$, nickel $(\mathrm{Ni})$, zinc $(\mathrm{Zn})$ and manganese $(\mathrm{Mn})$ may be released from various parts of the vehicle's internal mechanics into roadside surroundings. These pollutants then tend to accumulate on the soil surface. Anthropogenic and natural process then whip these dust particles in to the air depositing a considerable amount on the foliage of roadside trees. The Sidr tree, is common in Qatar and usually found planted in houses, gardens and roadsides. It is a strong grower in Qatar harsh environments and its flowering and fruiting in spring season (March-April). This current study was conducted to gauge the heavy metal deposition on the leaves of the Sidr tree by the roadside as a first step in evaluating the use of this plant as a bio-monitor of environmental pollution.
2. Methods

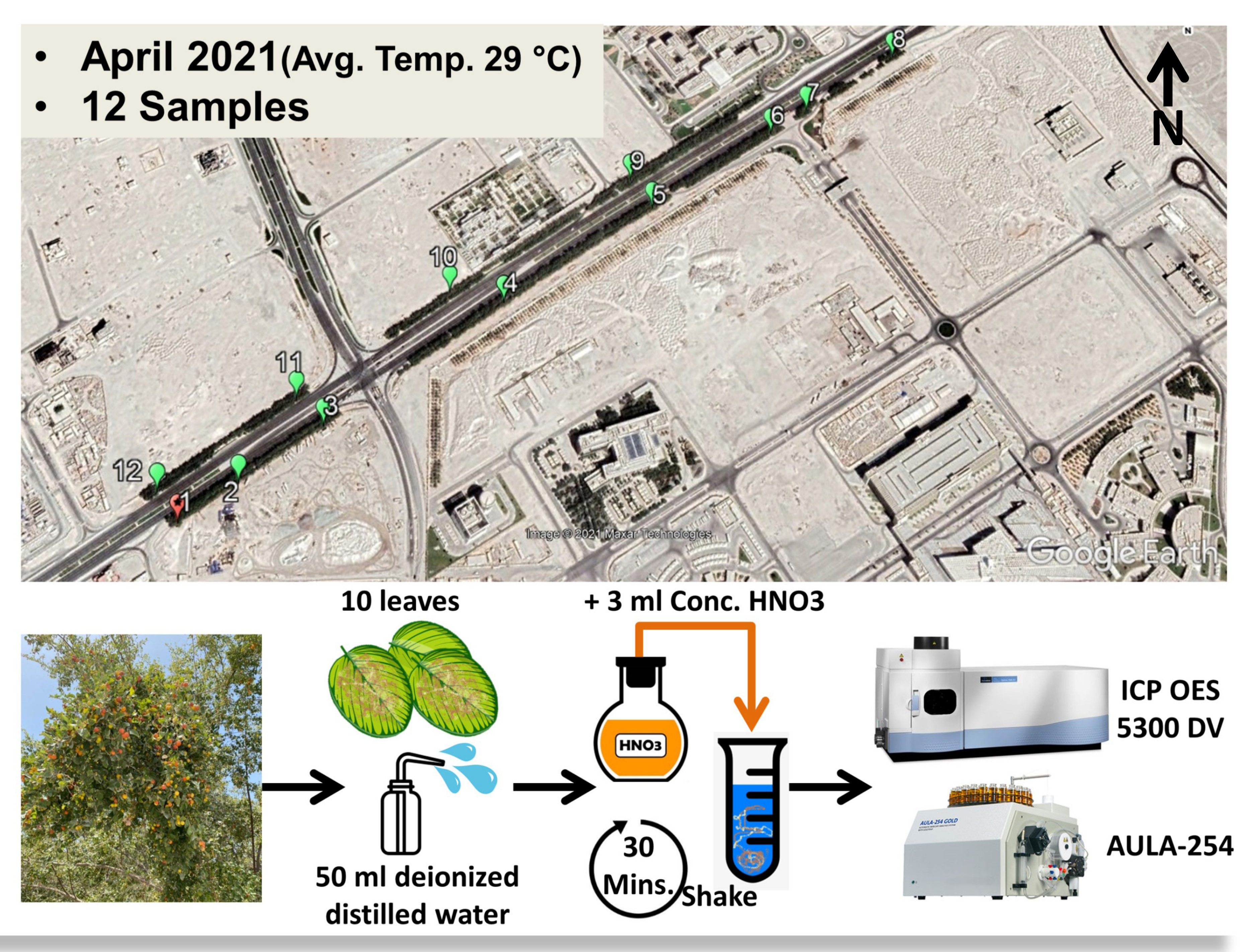

\section{Results}

-Highest concentration recorded in location 1 (denoted on map by $\odot$ ). -Location 1: heavy digging and construction work, parking trucks, buses - Strong positive correlation - Similar distribution of trace metals in leaf dust samples from our study and Southwestern Iran

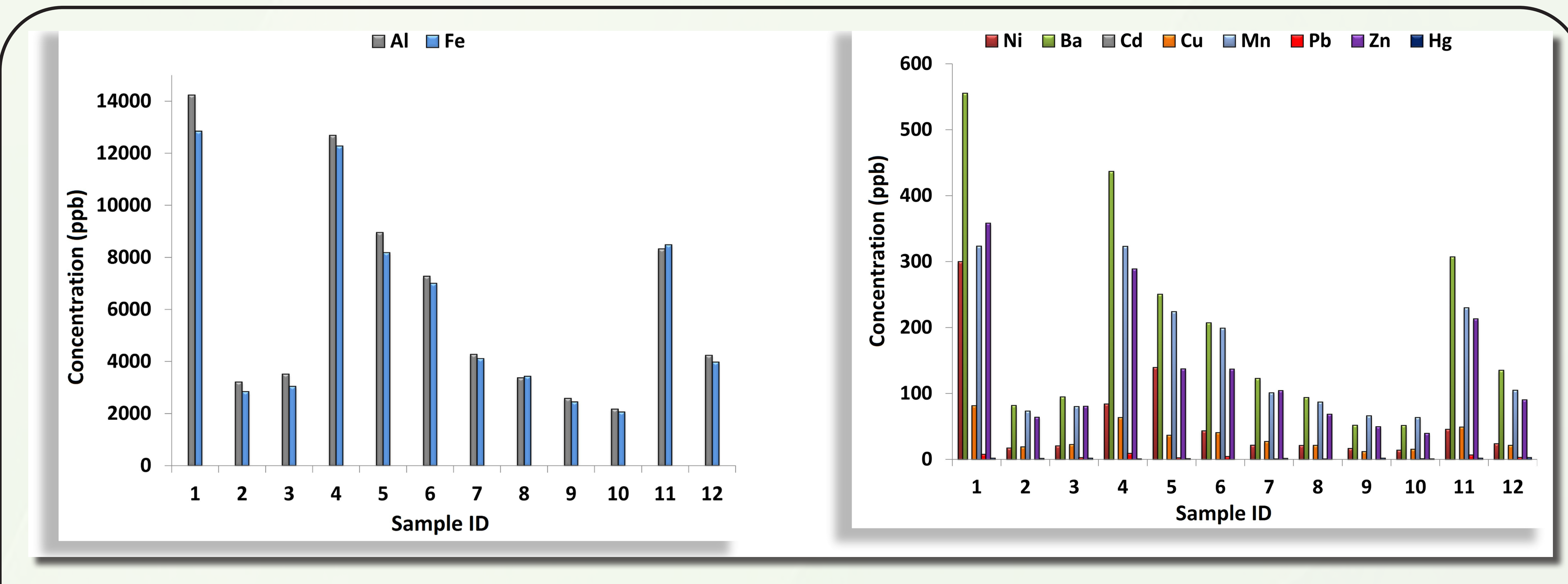

Heavy metal concentration (ppb) in leaf dust sample from the study area
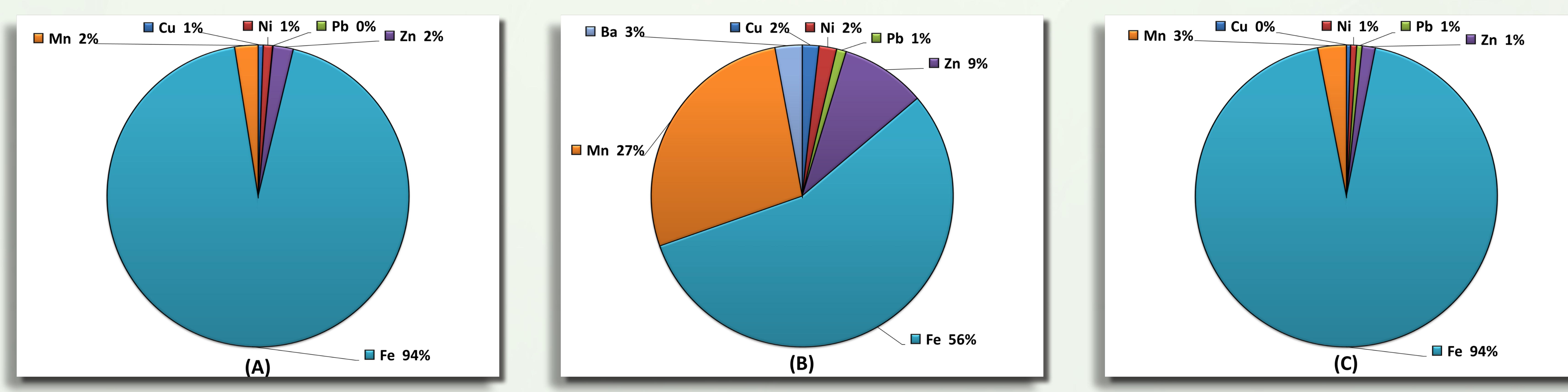

Distribution of trace metals in leaf dust samples. (A) Qatar, (B) Hungary, (C) Southwestern Iran

\section{Ongoing Work}

- Analysis of control sample ( collected from farm).

- Seasonal collection.

- Air pollution index.

\section{References}

Hrotkó, K., Gyeviki, M., Sütöriné, D. M., Magyar, L., Mészáros, R., Honfi, P., \& Kardos, L. (2021). Foliar dust and heavy metal deposit on leaves of urban trees in Budapest (Hungary). Environmental Geochemistry and Health, 43(5), 1927-1940

Naderizadeh, Z., Khademi, H., \& Ayoubi, S. (2016). Biomonitoring of atmospheric heavy metals pollution using dust deposited on date palm leaves in southwestern Iran. Atmósfera, 29(2), 141-155.

- Simon, E., Baranyai, E., Braun, M., Cserháti, C., Fábián, I., \& Tóthmérész, B. (2014). Elemental concentrations in deposited dust on leaves along an urbanization gradient. Science of the Total Environment, 490, 514-520. 